\title{
On an experiment in electricity
}

\section{James Watson Esq.}

To cite this article: James Watson Esq. (1837) On an experiment in electricity, Philosophical Magazine Series 3, 10:61, 326-327, DOI: 10.1080/14786443708649161

To link to this article: http://dx.doi.org/10.1080/14786443708649161

曲 Published online: 01 Jun 2009.

Submit your article to this journal 준

LII Article views: 2

Q View related articles $₫$ 
into deutoxide (oxide ferrosoferrique) and mercury into protoxide, whilst tin and lead are very slightly acted upon by this acid.

When per-iodic acid is neutralized by carbonate of soda, and precipitated by neutral nitrate of barytes, the resulting liquid is acid; this is also the case with the neutral salts of lead and lime, indi. cating the precipitation of a subsalt. Per-iodate of lead is white, but becomes yellow by heat, owing to its losing water. Similar phænomena occur with the proto- and bi-salts of mercury, the former changing from a yellow to a reddish brown, and the latter from white to yellow, by the application of a gentle heat. Periodate of soda gives a green precipitate with copper salts, which becomes more intense by heat, and the proto- and per-salts of iron form yellow precipitates. All these precipitates readily dissolve in dilute nitric acid.-Journ. de Pharmacie, Oct., 1836.

\section{ON AN EXPERIMENT' IN ELECTRICITY. BY JAMES WATSON, ESQ -}

To the Editors of the Philosophical Magazine and Journal.

\section{Gentlemen,}

As the following experiment may easily be made by any person who has an electrical machine, $I$ think it will be acceptable to many of your readers.

Take a slip of card about one inch in length and one quarter of an inch in breadth, and at one end of the card make a slit up the middle one quarter of an inch long; then bend out the divided parts in opposite directions, so that the bit of card may be made to stand upright upon its two short legs. By this means the card may be so nicely adjusted that a very slight touch will overbalance it, and cause it to fall. Now take two pieces of stout brass wire, four inches in length and pointed at each end; bend the wires at right angles, in order that each wire may have a short arm or stem, one inch long. These short arms or stems are to be inserted a little way into two holes made to receive them in a flat thick piece of wood. The two holes must be made at such a distance from each other that the points of the twolong horizontal arms shall be just threequarters of an inch apart. Midway between these points place the bit of card, in an upright position, as in the figure, where $C$ represents the edge of the card, baving its two flat sides opposite to the points of the two wires, $A$ and $B$.

To insure success in making this delicate experiment, the machine must be screwed to a very steady table, otherwise the card will be disturbed by the turning of the cylinder. The best way of making the discharge is to suspend a small jar from the prime conductor, and let the jar discharge itself through the electrometer. A chain must connect the electrometer with the wire $A$, and another chain must connect the outer coating of the jar with the wire $B$.

When the experiment is well performed, I always find that the card is perforated, and has a bur on each side of it, but what de- 
serves particular notice is the very curious fact that the card is not thrown down.

If two bits of card be placed between the wires, instead of one as in the last experiment, even then the separate bits of card will continue to stand, although both will be perforated.

The motion of a single fluid from the positive to the negative wire, cannot, I think, be reconciled with my experiment, which seems to require two equal repulsive actions.

I am, Gentlemen, your obedient servant,

Loudon, Jan. 31, 1837.

James Watson.

VOLUNTARY SOUNDS OF INSECTS.

We have received the following communication from a Correspondent relative to Dr. Burmeister's paper "On the Cause of Sound produced by Insects in Flying," printed in the Third tart of the Scientific Memoirs; in which it is shown not to be caused by the vibration of the wings, but by peculiar organs placed in the thorax, a minute account and delineation of which are given.

"I have several times tried the following experiment on the common large blue fly (Musca vomitoria). While it has been flying about the room with its usual buzzing noise, I have placed a small piece of meat on a table, and opened the duor of the room. The fly seems to be soon attracted by the meat, and on approaching and hovering over it the buzz has appeared to increase in loudness; but if, when it has been thus hovering over the table, I have caught at it with my hand, or attempted to strike it with a handkerchief, it has immediately flown away, and generally out at the door, without producing the slightest audible sound, as though it intended to conceal the direction of its flight."

$\mathrm{X}$.

[I have often witnessed the silent flight of this insect on being disturbed or attempted to be caught, exactly as described by our Correspondent._E. W. B.]

\section{METEOROLOGICAL OBSERVATIONS FOR FEBRUARY 1837.}

Chiswick.-Feb. 1. Foggy: slight frost. 2. Foggy: fine. 3. Hazy. 4. Frosty : fine. 5. Overcast. 6, 7. Sharp frost : very fine. 8. Overcast : rain. 9. Fine. 10. Fine: rain: stormy at night. 11. Boisterous, with rain : lightning at night. 12. Clear: cloudy and fine : rain. 13. Rain : fine. 14. Very fine. 15. Foggy. 16,17. Fine. 18. Slight rain: cloudy : stormy: about $\frac{1}{2}$ past 10 P.M. a reddish luminous arch was observed, extending through the zenith, in a direction nearly east and west. 19. Overcast: stormy with heavy rain. 20. Very clear: fine. 21. Stormy with rain : fine. 22. Clear and fine. 23. Stormy with rain. 24. Clear and cold. 25, 26. Cold and bleak. 27, 28. Overcast.

Boston-Feb. 1. Foggy. 2. Cloudy. 3, 4. Fine. 5-7. Cloudy. 8. Fine. 9. Cloudy. 10. Stormy. 11. Rain and stormy : rain early A.M. 12-14. Fine. 15. Cloudy. 16,17. Fine. 18. Cloudy: stormy with rain P.M. 19. Cloudy : rain P.M. 20. Cloudy: 21. Fine : rain early A.M.: rain P.M. 22. Cloudy, 23. Rain: stormy night. 24. Stormy. 25. Fine : snow P.M. 26. Fine. 27. Cloudy. 28. Fine. 